\title{
Alkylation of Benzene with 1-Dodecene over USY Zeolite Catalyst: Effect of Pretreatment and Reaction Conditions
}

\author{
Xing-Dong Yuan, Jung-Nam Park, Jun Wang*, Chul Wee Lee ${ }^{\dagger}$ and Sang-Eon Park ${ }^{\dagger}$ \\ Catalysis Center for Molecular Engineering, Korea Research Institute of Chemical Technology (KRICT), \\ P.O. Box 107, Yusung, Daejeon 305-600, Korea \\ (Received 7 March 2002 • accepted 10 May 2002)
}

\begin{abstract}
Catalytic activity, stability and selectivity of USY zeolite catalyst for alkylation of benzene with 1-dodecene were investigated using a continuous fixed bed high pressure microreactor. It is found that the catalytic activity and stability depend closely on the pretreatment temperature of catalyst and reaction conditions. The best result was obtained at $120^{\circ} \mathrm{C}$ and $3.0 \mathrm{MPa}$ with 8 molar ratio of benzene to 1-dodecene, and $4 \mathrm{~h}^{-1}$ weight hourly space velocity of reactant over the catalyst with the pretreatment temperature of $500{ }^{\circ} \mathrm{C}$. Under this condition, the reaction conversion was nearly $100 \%$ and no deactivation was observed within the employed $50 \mathrm{~h}$ of time on stream with the selectivity of 2-phenyldodecene being $22 \%$.
\end{abstract}

Key words: Linear Alkylbenzene, USY Zeolite, Alkylation, 1-Dodecene, Benzene

\section{INTRODUCTION}

Linear alkylbenzene (LAB) is the primary raw material used to produce LAB sulfonate (LAS), a surfactant detergent intermediate. Nowadays, most of LAB productions involve the utilization of hydrofluoric acid as the catalyst, which is a source of pollution and equipment corrosion. A great deal of effort has been concentrated on the development of solid acid catalysts for the process. Recently, UOP and CEPSA announced their new Detal process for the manufacture of LAB based on a fixed bed of solid acid catalyst, which is fluoride containing silica-alumina [Kocal, 1993; Sivasanker and Thangaraj, 1992].

Among various solid acid materials, zeolites have been extensively evaluated for the production of LAB [Kocal et al., 2001]. For example, H-ZSM-5 and H-ZSM-12 show little activity due to their small pore size, and dealumination of mordenite or Y zeolite can increase the catalytic activity and stability by opening up the mesoporosity with the zeolite [Jung et al., 2000; Meriaudeau et al., 1997; Sugi et al., 2000]. Zeolite Beta and EMT are also evaluated together with Y zeolite, and it is found that Beta and EMT catalysts are less active than Y zeolite [Cao et al., 1999].

So far, the catalytic stability of zeolite is still a key problem need to be solved for the future commercial utilization of zeolite catalysts in LAB production. However, only a few studies have adopted fixed bed reactor to evaluate the catalyst performance [Sivasanker and Thangaraj, 1992], and most of the previous experiments are carried out in batch reactors, which are inconvenient for testing the catalytic stability.

\footnotetext{
To whom correspondence should be addressed.

E-mail: separk@krict.re.kr or chulwee@krict.re.kr

This paper is dedicated to Professor Wha Young Lee on the occasion of his retirement from Seoul National University.

*On a research leave from Department of Chemical Engineering, Nanjing University of Technology, Nanjing 210009, China.
}

In this work, the activity, selectivity and stability of an USY zeolite catalyst are measured in detail in the alkylation of benzene with 1-dodecene under various pretreatment and reaction conditions. We consider that, during the water steam treatment for the preparation of USY zeolite, acid strength increases and acid number decreases, with the creation of secondary structured mesopores. These catalyst properties are indispensable for the high performance of the zeolite catalyst in the reaction of benzene alkylation with 1-dodecene.

\section{EXPERIMENTAL}

All experiments were carried out in a fixed bed microreactor. The reactant mixture of benzene and 1-dodecene was injected by a high pressure pump into the fixed bed reactor, in the middle stage of which was charged with $1.0 \mathrm{~g}$ of USY catalyst in the form of granules (4060 mesh). The catalyst was initially pretreated in situ in air flow at a desired temperature before reactants enter the reactor. In order to measure the effect of reaction conditions, reactions were operated in a temperature range of $80-160^{\circ} \mathrm{C}$, at a pressure interval of 0.1 3.0 MPa, with the molar ratio of benzene to 1-dodecene (B/D) in a range of 2-8, and weight hourly space velocity (WHSV) of the reactant of 4-12 $\mathrm{h}^{-1}$. Also, to keep the system at the required pressure, a small flow of $\mathrm{N}_{2}$ was maintained from the reactor head. The reaction products were analyzed by the gas chromatograph (HP 5890 II) using FID as the detector furnished with a $30 \mathrm{~m}$ SE30 capillary column. The conversion and selectivity were calculated as follows. Conversion $=\left(M_{d 0}-M_{d}\right) / M_{d 0} \times 100 \%$, where $M_{d 0}$ is the molar percentage of 1-dodecene before reaction, and $\mathrm{M}_{d}$ is the molar percentage of 1-dodecene after reaction. Selectivity of LAB isomer was defined as $\mathrm{S}=\mathrm{M}_{1} / \mathrm{M}_{t} \times 100 \%$, where $\mathrm{M}_{1}$ is the molar percentage of a LAB isomer in the final products, and $\mathrm{M}_{t}$ is the sum of molar percentage of all six phenyldodecane isomers.

Zeolite USY used in this work was from Zeolyst $(\mathrm{Si} / \mathrm{Al}=40)$. Benzene was from Wako (99.0\%) and 1-dodecene from Tokyo Kasei $(95.0 \%)$. The reactants were dehydrated by $5 \mathrm{~A}$ zeolite before use. 

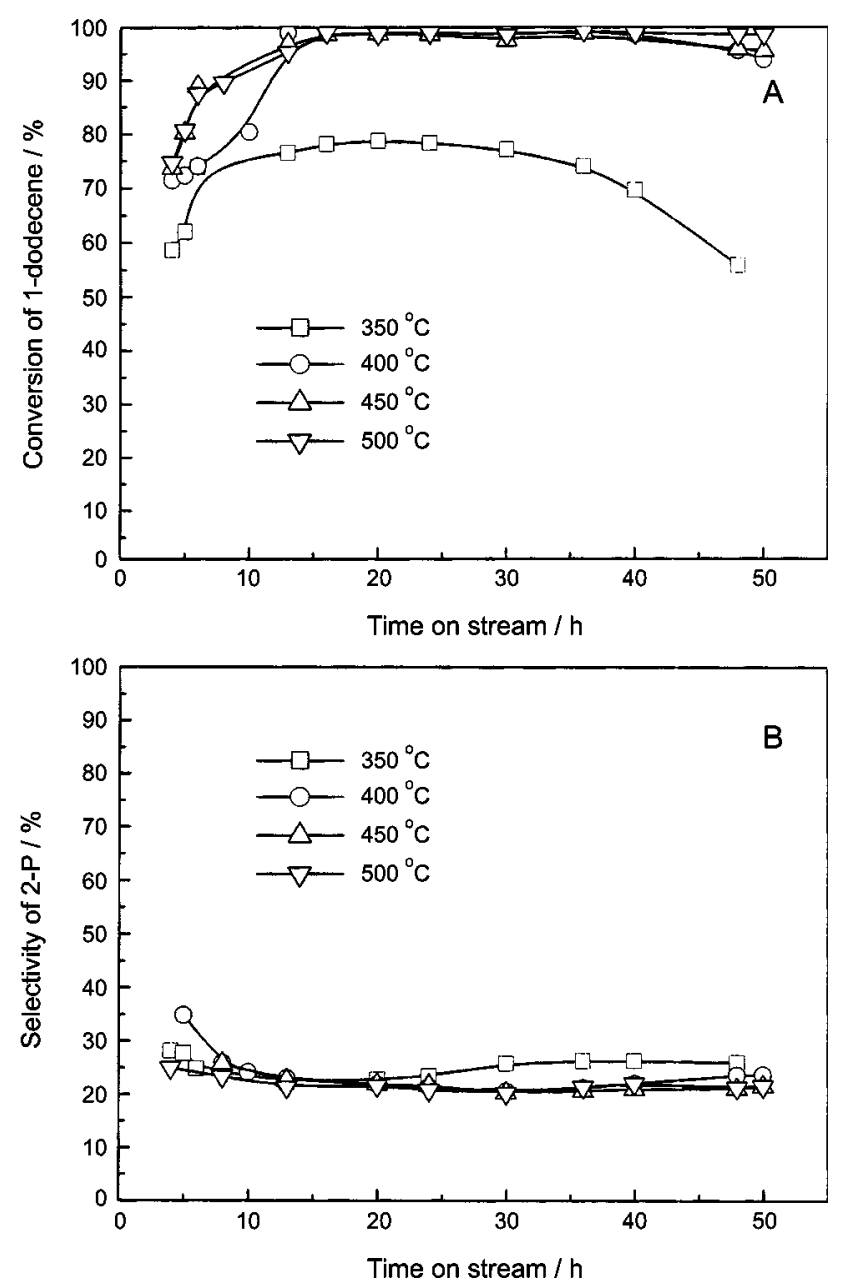

Fig. 1. Alkylation of benzene with 1-dodecene over USY zeolite catalyst: effect of pretreatment temperature of the catalyst in air flow for $4 \mathrm{~h}$ on activity and stability (A), and selectivity (B) (Reaction temperature $=120{ }^{\circ} \mathrm{C}$, Pressure $=3.0 \mathrm{MPa}$, $\left.\mathrm{WHSV}=4 \mathrm{~h}^{-1}, \mathrm{~B} / \mathrm{D}=8\right)$.

\section{RESULTS}

\section{Effect of Pretreatment Temperature of USY Catalyst}

The experiment was carried out at $120^{\circ} \mathrm{C}$ and $3.0 \mathrm{MPa}$, and with the WHSV of $4 \mathrm{~h}^{-1}$ and the B/D of 8, which is the typical reaction condition in this work. Fig. 1 shows the influence of pretreatment temperature of USY zeolite in air on the reactivity of alkylation of benzene with 1-dodecene. At all pretreatment temperatures in Fig. 1A, conversion of 1-dodecene increases gradually at the early stage of time on stream. At the pretreatment temperature of 400, 450, or $500{ }^{\circ} \mathrm{C}$, the conversion gets to a plateau with a same conversion level of about $100 \%$ after ca. $15 \mathrm{~h}$ of time on stream, by contrast, at 350 ${ }^{\circ} \mathrm{C}$, the conversion reaches a maximum point of about $75 \%$ which is far lower than the other three catalysts, at a time on stream of ca. $20 \mathrm{~h}$, after which, a rapid deactivation of the catalyst occurs. A slow deactivation is also observed for the other two catalysts pretreated at 400 or $450{ }^{\circ} \mathrm{C}$, when time on stream is beyond $40 \mathrm{~h}$. By contrast, for the catalyst pretreated at $500{ }^{\circ} \mathrm{C}$, no deactivation is found during all time on stream employed. On the other hand, for all catalysts, Fig. 1B shows at the early stage of reaction a decrease of the

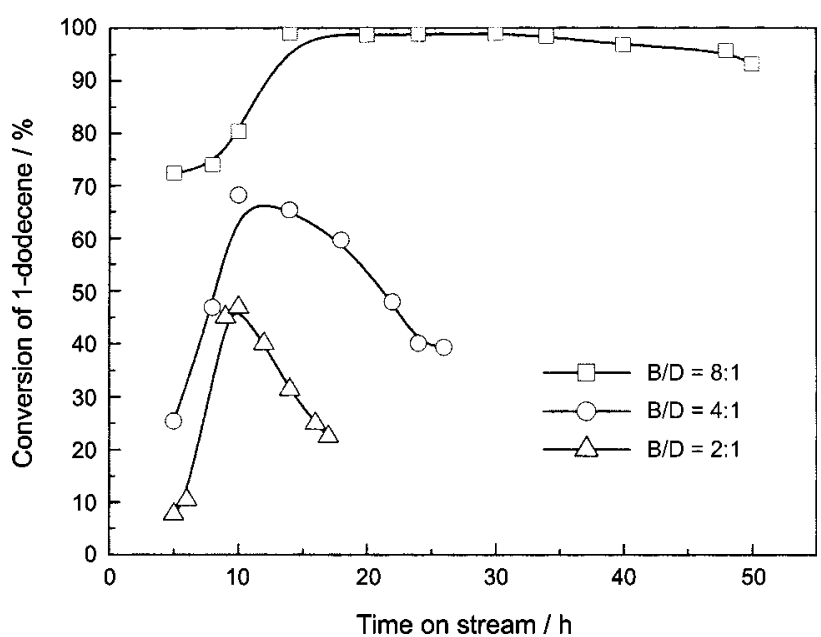

Fig. 2. Alkylation of benzene with 1-dodecene over USY zeolite catalyst: effect of ratio of benzene to 1-dodecene (Reaction temperature $=120{ }^{\circ} \mathrm{C}$, Pressure $=3.0 \mathrm{MPa}, \mathrm{WHSV}=4 \mathrm{~h}^{-1}$, Pretreatment temperature $=400{ }^{\circ} \mathrm{C}$ ).

selectivity of 2-phenyldodecane (2-P), which is the most desired isomer among the reaction products because it gives detergent of better emulsibility and biodegradability. At the last half of the reaction time on stream, the selectivity is stable, except that an increase of selectivity of 2-P is observed on the catalyst pretreated at $350{ }^{\circ} \mathrm{C}$.

\section{Effect of the Molar Ratio of Benzene to 1-Dodecene}

The experiment was performed at the typical reaction condition with the pretreatment temperature being $400^{\circ} \mathrm{C}$. The effect of $\mathrm{B} / \mathrm{D}$ on the catalytic activity and stability of the USY catalyst is displayed in Fig. 2. It can be seen in Fig. 2 that the conversion of 1dodecene increases obviously with the increase of benzene content in the reactant mixture, and moreover, at low B/D values, the catalyst is observed to deactivate quickly. It is also found in Fig. 2 that the higher the $\mathrm{B} / \mathrm{D}$ is, the longer reaction time on stream is needed for the catalyst to reach its maximum activity.

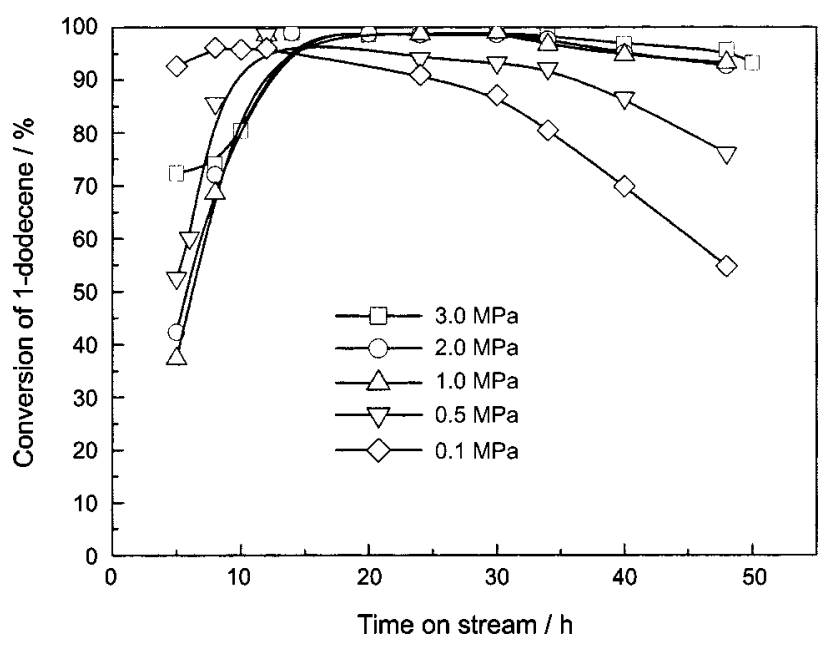

Fig. 3. Alkylation of benzene with 1-dodecene over USY zeolite catalyst: effect of reaction pressure (Reaction temperature $=$ $120^{\circ} \mathrm{C}, \mathrm{WHSV}=4 \mathrm{~h}^{-1}, \mathrm{~B} / \mathrm{D}=8$, Pretreatment temperature $=$ $\left.400{ }^{\circ} \mathrm{C}\right)$. 


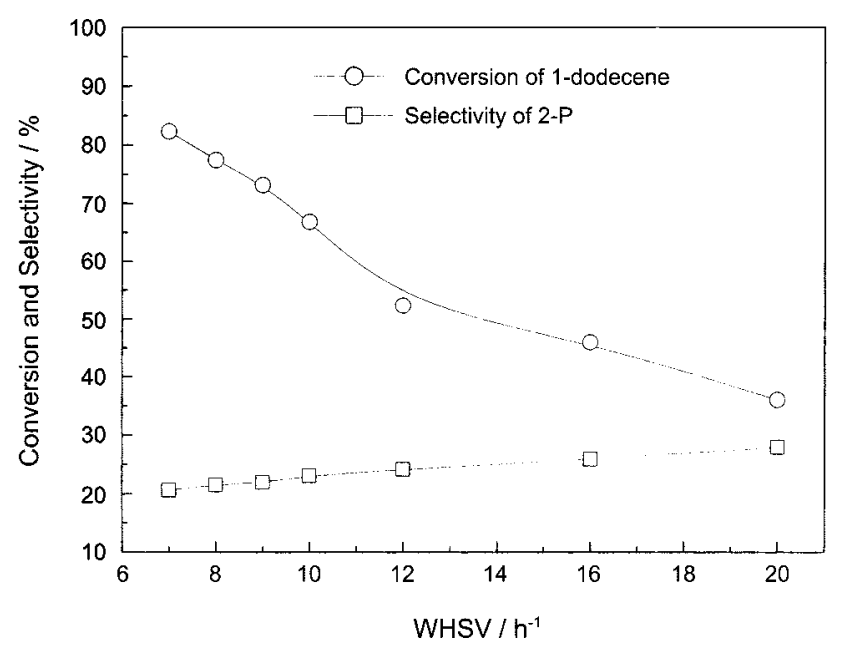

Fig. 4. Alkylation of benzene with 1-dodecene over USY zeolite catalyst: effect of weight hourly space velocity of the reactant (Reaction temperature $=120^{\circ} \mathrm{C}$, Pressure $=3.0 \mathrm{MPa}, \mathrm{B} / \mathrm{D}=8$, Pretreatment temperature $=400^{\circ} \mathrm{C}$ ).

\section{Effect of Reaction Pressure}

Fig. 3 exhibits the effect of reaction pressure on the catalytic activity as a function of reaction time on stream. It is clearly observed that at the pressure lower than 1.0 MPa, no stabilized activity can be achieved, while at the high pressures, the catalyst gives similar results: after ca. $15 \mathrm{~h}$ of time on stream, stabilized conversion higher than $95 \%$ can be obtained.

\section{Effect of the Space Velocity of Reactant Mixture}

The experiment was measured at $100{ }^{\circ} \mathrm{C}$ and $3.0 \mathrm{MPa}$, with the pretreatment temperature of $400^{\circ} \mathrm{C}$ and the B/D of 8. Fig. 4 indicates that the conversion of 1-dodecene decreases with the increase of WHSV, and meanwhile, the selectivity of 2-P gradually increases with the decrease of conversion.

\section{Effect of Reaction Temperature}

The effect of reaction temperature on the catalytic activity, stability and selectivity is shown in Table 1 . It is found that at all employed temperatures very high conversion of 1-dodecene is obtained at the reaction time on stream of $20 \mathrm{~h}$, however, the higher the reaction temperature is, the lower the final conversion is observed. As for the selectivity, whatever the reaction temperature and time on stream, no obvious discrepancy of selectivity of 2-P is observed.

Table 1. Conversion of 1-dodecene and selectivity of 2-P as a function of reaction temperature ${ }^{a}$

\begin{tabular}{cccc}
\hline \hline $\begin{array}{c}\text { Temperature } \\
/{ }^{\circ} \mathrm{C}\end{array}$ & $\begin{array}{c}\text { Time on stream } \\
/ \mathrm{h}\end{array}$ & $\begin{array}{c}\text { Conversion } \\
/ \%\end{array}$ & $\begin{array}{c}\text { Selectivity } \\
/ \%\end{array}$ \\
\hline \multirow{2}{*}{80} & 20 & 98.4 & 26.0 \\
& 50 & 96.7 & 23.2 \\
\multirow{2}{*}{120} & 20 & 98.6 & 22.0 \\
& 50 & 93.2 & 23.7 \\
160 & 20 & 98.6 & 21.2 \\
& 50 & 79.2 & 22.6 \\
\hline
\end{tabular}

${ }^{a}$ Reaction Pressure $=3.0 \mathrm{MPa}, \mathrm{B} / \mathrm{D}=8$, Pretreatment temperature $=$ $400{ }^{\circ} \mathrm{C}$

\section{DISCUSSION}

The alkylation of benzene with 1-dodecene takes place via a carbonium ion mechanism at the acid site of catalyst. Six carbonium ions possibly appeare due to the double bond isomerization of 1dodecene. According to the stabilities of them, one would expect the content of produced phenyldodecane isomer to increase with the carbon number (toward the center of the dodecane chain), and in fact, 1-phenyl isomer is not detected in the product, due to the very low stability of the primary ion. This is found to be so in case of $\mathrm{HF}$, in which thermodynamic equilibrium is probably reached [Sivasanker and Thangaraj, 1992]. However, on the heterogeneous acidic catalyst with a pore structure like zeolite, it is expected that the catalytic activity, selectivity and stability would be influenced by catalyst acidity (acid density, acid strength and acid type), pore structure of zeolite and location of acid sites. For instance, polymers produced on acid sites in small pores through polymerization of dodecene will block the pores and lead to the deactivation of catalyst. It is proposed that there would be optimum performance with the most acid sites coupled with the most open mesoporosity in catalyst [Meriaudeau et al., 1997].

The acidity of zeolite relates closely to the pretreatment temperature. For USY, both acid strength and acid number increases with the calcination temperature, with the release of proton in zeolite crystal pore by dehydration. At very high calcination temperature, two Brönsted acid sites transform into one strong Lewis acid site, resulting in the decrease of acid density, and at the same time, slight dealumination occurs with the generation of more secondary mesopores [de Almeida et al., 1994]. Therefore, the observation in Fig. 1 A that the catalysts pretreated at high temperatures $\left(\geq 400^{\circ} \mathrm{C}\right)$ display higher activities than the one at low temperature $\left(350^{\circ} \mathrm{C}\right)$ corresponds well with the enhancement of number of strong acid site produced at high pretreatment temperature. Through FT-IR characterization results of a series of modified $\mathrm{H}$-mordenite zeolites, a recent literature [Wang et al., 2001] found the sum of the numbers of strong Brönsted and Lewis acid centers exhibits a most similar trend with the conversion of the benzene alkylation with 1-dodecene, and thus the authors indicated that both strong Brönsted and Lewis acid sites are responsible for this reaction. For the catalyst pretreated at $350^{\circ} \mathrm{C}$, there dominate weak and medium strong acid sites, which are supposed to be favorable to the polymerization of dodecene and the catalyst pores are clogged easily, and thus deactivation occurs quickly. Accompanying with the deactivation of the catalyst pretreated at $350{ }^{\circ} \mathrm{C}$, the selectivity of 2-P is apparently increased (Fig. 1B). This is considered to arise from the shape selectivity of the more narrow pores formed by the part blockage of zeolite channel. For the catalyst pretreated at $500{ }^{\circ} \mathrm{C}$, the acid density deceases, but the acid strength increases simultaneously, with the number of mesopores being enhanced. This may accounts for its always high activity and stable selectivity. On the other hand, at its stabilized stage, the selectivity of 2-P is around $22 \%$, which is just slightly higher than that of HF [Sivasanker and Thangaraj, 1992], and shows no shape selectivity. This is because the wide-pore system of Y zeolite that is largely retained, together with plenty of mesopores that are favorable to mass transfer during the reaction.

Not only pretreatment temperature, but also reaction conditions drastically affect the reaction result. When B/D drops to a low value, 
dodecene has more chance to polymerize into polyolefins, therefore the zeolite pore tends to be blocked easily in this case, which causes the short life of the catalyst (Fig. 2). In addition, high reaction temperature can also lead to the comparatively quick deactivation of catalyst. It could be expected that the tendency of the polymerization of dodecene would be raised by high reaction temperature, which might be the reason for the deactivation of catalyst in Table 1 at the high reaction temperature of $160^{\circ} \mathrm{C}$.

An important observation in this work is that for most of experiments, an increase of catalytic activity is found with time on stream at the early reaction stage (Figs. 1-3). In a batch reactor, a previous report revealed that the used HY zeolite could be regenerated by the hot benzene [Liang et al., 1996]. Thus, one could reasonably consider that benzene is not only a reactant, but also a solvent, which can partly refresh the deactivated acid sites by dissolving the polymers produced on acid sites locating in zeolite channel through dodecene polymerization. Based on the above consideration, it is deduced that at the very initial reaction time on stream, a large amount of polymers are generated and thus block the zeolite pores, however, this is partly compensated by the dissolution of polymers by benzene solvent at a comparatively low speed, with the release of a part of strong acid sites being active for alkylation. This could be the explanation for the increment of alkylation activity at the early stage of time on stream. The increment of B/D leads to the rapid dissolution of polyolefin and thus the catalyst can reach the maximum activity point at a short time on stream (Fig. 2). The only exception is found in Fig. 3 on the catalyst performed at $0.1 \mathrm{MPa}$, in which the reaction actually takes place in gas phase, and no solvent effect could be expected, as a result of which, the activity decreases from the very beginning of the reaction.

\section{CONCLUSIONS}

Through detailed experiments for benzene alkylation with 1-dodecene over a USY zeolite catalyst with a continuous high pressure fixed bed reactor, the following conclusions are obtained:

1. Pretreatment temperature and reaction conditions drastically influence the catalytic activity and stability, by contrast, slightly influence catalytic selectivity. Increase of pretreatment temperature can enhance the catalyst acid strength, decrease acid density, and create more mesopores [de Almeida et al., 1994; Sasaki et al., 1998], which is indispensable for the high catalytic activity and stability. High B/D value and reaction pressure are favorable to the enhancement of catalytic activity and stability, but high reaction temperature causes the deactivation of catalyst.

2 . At the early reaction stage, an increase of alkylation activity is found in all experiments. This is supposed to originated from refreshment of a part of strong acid sites in zeolite pores by the competition between the quick polymerization of dodecene on acid sites and the slow dissolution of a part of thus produced light polymers into benzene solvent.

3. It is found that USY catalyst pretreated at $500^{\circ} \mathrm{C}$ in air flow for $4 \mathrm{~h}$ has a very high activity (near $100 \%$ ) and stability (no deactivation being observed within the employed $50 \mathrm{~h}$ time on stream), and a slightly higher selectivity (23\%) than that of $\mathrm{HF}$, when the reaction was carried out at $120^{\circ} \mathrm{C}, 3.0 \mathrm{MPa}$, with the WHSV and B/D being $4 \mathrm{~h}^{-1}$ and 8 , respectively.

\section{ACKNOWLEDGEMENTS}

This research was supported by the Ministry of Environment and the Ministry of Science and Technology.

\section{REFERENCES}

Cao, Y., Kessas, R., Naccache, C. and Ben Taarit, Y., "Alkylation of Benzene with Dodecene. The Activity and Selectivity of Zeolite Type Catalysts as a Function of the Porous Structure,' Appl. Catal. A: General, 184, 231 (1999).

de Almeida, J. L. G., Dufaux, M., Ben Taarit, Y. and Naccache, C., "Effect of Pore Size and Aluminium Content on the Production of Linear Alkylbenzenes over HY, H-ZSM-5 and H-ZSM-12 Zeolites: Alkylation of Benzene with 1-Dodecene,' Appl. Catal. A: General, 114, 141 (1994).

Jung, J.-H., Lee, J.-K., Kim, J. K. and Lee, H. K., "p-Selectivity of the Al-MFI Substituted Series in Alkylation of Toluene,' Korean J. Chem. Eng., 17, 461 (2000).

Kocal, J. A., US Patent, 5,136,574 (1993).

Kocal, J. A., Vora, B. V. and Imai, T., "Production of Linear Alkylbenzenes,' Appl. Catal. A: General, 221, 295 (2001).

Liang, W., Jin, Y., Yu, Z., Wang, Z. and Han, B., "Alkylation of Benzene with Dodecene over HY Zeolite: Deactivation, Regeneration, and Product Distribution,' Zeolites, 17, 297(1996).

Meriaudeau, P., Ben Taarit, Y., Thangaraj, A., Almeida, J. L. G. and Naccache, C. ,"Zeolite Based Catalysts for Linear Alkylbenzene Production: Dehydrogenation of Long Chain Alkanes and Benzene Alkylation,' Catal. Today, 38, 243 (1997).

Sasaki, Y., Suzuki, T., Takamura, Y., Saji, A. and Saka, H., "Structure Analysis of the Mesopore in Dealuminated Zeolite Y by High Resolution TEM Observation with Slow Scan CCD Camera,' J. Catal., 178(1), 94 (1998).

Sivasanker, S. and Thangaraj, A., "Distribution of Isomers in the Alkylation of Benzene with Long-Chain Olefins over Solid Acid Catalysts,' J. Catal., 138, 386 (1992).

Sugi, Y., "Shape-Selective Alkylation of Biphenyl Catalyzed by H-Mordenites,' Korean J. Chem. Eng., 17, 1 (2000).

Wang, B., Lee, C. W., Cai, T. and Park, S. E., "Benzene Alkylation with 1-Dodecene over H-mordenite Zeolite,' Catal. Lett., 76(1-2), 99 (2001). 